\title{
Study on the wear resistance of laser cladding iron-based alloy by heat treatment
}

\author{
Wei Guo ${ }^{1}$, Liping Zhang ${ }^{1}$, Chao $\mathrm{Xu}^{1 *}$, Bridget $\mathrm{Kogo}^{2}$, Rongxia Chai ${ }^{1}$, Mahmoud Chizari $^{2}$, \\ Chuanwei Zhang ${ }^{1}$, Bin Wang ${ }^{2}$ \\ ${ }^{1}$ School of Mechanical Engineering, Xi'an University of Science and Technology, No.58 Yanta Rd, \\ Xi'an, Shaanxi, P.R. China, 710054 \\ ${ }^{2}$ School of Engineering and Design, Brunel University, UK
}

\begin{abstract}
The wear resistance of laser cladding iron-based alloy experiment has been carried out by the friction and wear experiment and a number of tests. Heat treatment of weld was further studied through microstructure observation, hardness test, the quality of wear and wear appearance. The results show that the crystalline grains of the heat treatment scheme are homogeneous and smaller. Meanwhile, the wear quality and friction coefficient are reduced and the wear morphology is improved. The wear situation of the non-heat treatment scheme revealed corrugated folds, tearing and adhesive bumps occurring in along friction surfaces whereas that of the heat treatment generated smooth surfaces and also confirms shallow fold and peeling along friction direction revealing the most preferred scheme.
\end{abstract}

\section{Keywords}

Heat-treatment, non-heat treatment, wear-resistance, wear morphology

\section{Introduction}

Welding is a joining technology used in the process of fabrication and manufacturing of engineering structures and offshore pipelines before laying them on the sea floor and prior to use in deep offshore operations. Up until now welding, particularly in cylindrical objects (most especially pipelines), has remained a source of concern due to its complexity. ${ }^{1-3}$

Within the aerospace industry, the norm in the repair of tool is tungsten inert gas (TIG) welding. However, there is the emergence of a new technology known as laser cladding. ${ }^{4,5}$ It is an efficient and high performance metal surface heat treatment method. The demand for reliable, long-lasting and safe engineering facilities, mode of operation and working environment are high in every industrial application. This spurs the need for joining dissimilar metals with the main aim of achieving enhanced and improved components with better mechanical and thermal properties, light weight and outstanding performance, as well as prolonged in-service life. ${ }^{6-8}$

Lasers used in industry is a technology which has a wide variety of applications and flexibility in medical, electronic, aerospace, automobile, computing and shipbuilding amongst other industries. ${ }^{9-11}$ The incorporation of optical fiber technology alongside robotics application via conveying this technique makes laser welding readily automated and straight forward in its maneuvering and application in manufacturing industry. ${ }^{12}$

The underground environment of coal mine is very harsh. Many impurities exist in the air, such as water mist, acid gas and solid particles, which will cause the hydraulic support column easily corroded and worn, seriously affects the normal use of the column (Figure 1). To address this problem, laser cladding technology was chosen to solve it. Laser cladding is a technology to coat a kind of material with special physical, chemical or mechanical properties on the surface of the substrate by a highenergy laser beam, followed by the rapidly melting, expanding and solidifying of this substrate material to form a new composite material. ${ }^{13}$ This will significantly improve the wear resistance, corrosion resistance, oxidation resistance and heat resistance and other properties of the substrate surface so that to make up the high performance that the substrate lack. Nevertheless, laser cladding belongs to a non-equilibrium process of rapid melting and rapid solidification, which leads to high residual stress and unstable microstructure in the coating. It will critically restrict the applications of industry due to the high residual stress and even cracks in the coating. Heat treatment, as an efficient method, can adjust microstructure and relieve residual stress of laser clad anti-wear coating to acquire the desired properties. Furthermore, heat treatment will be beneficial to the anti-wear composite coatings during the long-term service process. Therefore, the microstructure and wear resistance of laser cladding samples after heat treatment were studied in this study. 
This new emerging technology has been shown in this study to be effective in cladding protective coating material on the component substrate, consequently generating a crack free and pore free coating. ${ }^{14-16}$ The impact of this research will be seen in the use of good performance metal surface heat treatment technology - laser cladding in the manufacture of mechanical parts. The novelty of this study is that we address the welding of two dissimilar materials - iron based alloy onto a 27SiMn steel substrate.

Another novelty of this study is the enhancement of the properties of laser clad anti-wear coating via heat treatment scheme. An effective weld between dissimilar metals is one in which the strength of the weld equals the weaker of the two metals being joined. This invariably means great tensile strength and ductility to prevent failure in the weld joint. The welding of two dissimilar materials entails generating a non-equilibrium solidification process consequently inducing high residual stress and instability in the coating microstructure; and eventually cracks. The presence of these cracks and high residual stresses limit the industrial applications of the coating to a critical level. 17-19

An efficient technique in relieving the residual stress and adjusting the microstructure of the laser clad anti-wear coating in order to achieve the desired qualities is post heat treatment. This procedure also has the added advantage of preserving antiwear coatings in service for long lasting effect. The properties such as heat resistance, corrosion resistance, oxidation resistance and surface resistance of the matrix material are enhanced when the surface coating is mixed with the latter.

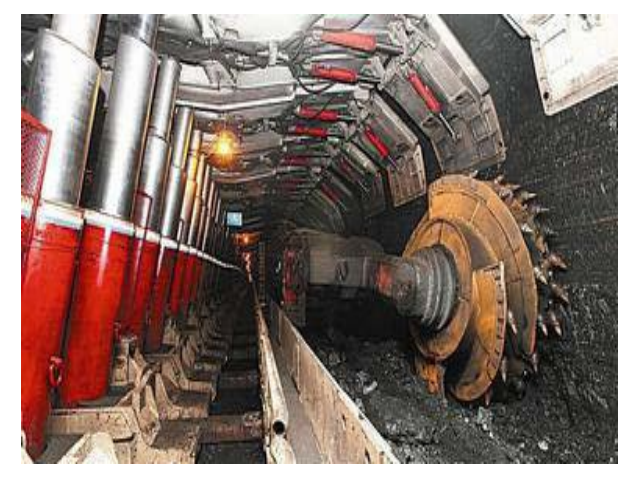

Figure1. Coal mine hydraulic support

\section{2 .Experimental set up}

2.1 Materials
The surface of the column is corroded and worn on account of the severe underground environment and the high strength working mode of the hydraulic support. In this study, 27SiMn steel is the column base material of mining hydraulic support which is selected as the substrate material of laser cladding. Its chemical component is shown in Table 1. According to the failure form of the column, the iron-based alloy powder was selected as the cladding layer material. Its chemical component content in the following Table 2, Cr of $15-17 \%$, Mn of $0.3-0.7 \%$ and $\mathrm{B}$ of $0.5-1.1 \%$, respectively, which will significantly improve the hardness of the material, in which the content of $\mathrm{Cr}$ more than $12 \%$, there are good high temperature anti-oxidation and oxidation resistance in steel. Besides, the contents of Si and Ni are $1.0-1.5 \%$ and $3.5-4.0 \%$, which improve the corrosion resistance of the material. Therefore, the composition of the ironbased alloy satisfy the experimental requirements by analyzing the content of the components.

Table 1. Chemical composition of 27SiMn steel

\begin{tabular}{cc}
\hline $\begin{array}{c}\text { Elements } \\
\text { composition }\end{array}$ & $\begin{array}{c}\text { Component } \\
\text { content (\%) }\end{array}$ \\
\hline $\mathrm{C}$ & $0.24-0.32$ \\
$\mathrm{Si}$ & $1.10-1.40$ \\
$\mathrm{Mn}$ & $1.10-1.40$ \\
$\mathrm{~V}$ & $0.07-0.12$ \\
$\mathrm{Ni}$ & $\leq 0.3$ \\
$\mathrm{Cu}$ & $\leq 0.3$ \\
$\mathrm{~S}$ & $\leq 0.3$ \\
$\mathrm{P}$ & $\leq 0.3$ \\
\hline
\end{tabular}

Table 2. Chemical composition of iron-based alloy powder

\begin{tabular}{cc}
\hline $\begin{array}{c}\text { Elements } \\
\text { composition }\end{array}$ & $\begin{array}{c}\text { Component } \\
\text { content (\%) }\end{array}$ \\
\hline $\mathrm{Cr}$ & $15.0-17.0$ \\
$\mathrm{Mn}$ & $0.3-0.7$ \\
$\mathrm{~B}$ & $0.5-1.1$ \\
$\mathrm{Si}$ & $1.0-1.5$ \\
$\mathrm{Mo}$ & $1.5-1.9$ \\
$\mathrm{Ni}$ & $3.5-4.0$ \\
$\mathrm{C}$ & $0.1-0.15$ \\
$\mathrm{Fe}$ & Bal \\
\hline
\end{tabular}

Iron-based alloy was clad onto 27SiMn steel substrate material having a hardness of 230 245HV. The surface of the sample is firstly polished with the sand paper prior to carry out the laser cladding. The next stage is to clean and dry the substrate by using alcohol degreasing cotton. The prepared powder is 
employed in this research to coat the iron-based alloy powder onto the substrate which is shown in Figure 2. The shielding gas helps to prevent the oxidation within the weld set up and procedure. This fusion welding process achieves coalescence via high energy concentrated coherent light beam which is focused on the joint of weld as illustrated in the schematic setup.

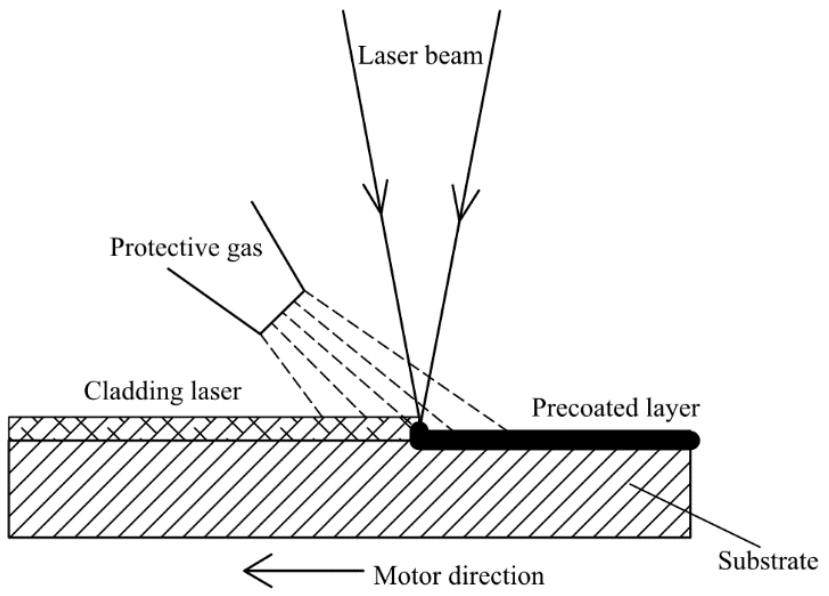

Figure 2. Schematic representations of laser cladding welding setup

2.2 Laser cladding processes

The effectiveness of fiber lasers in welding and cladding as well as cutting processes is unparalleled and attracted global focus within the last decade. ${ }^{20,21}$ The features of fiber lasers entail high precision, small beam divergence, reliability, compact size, high efficiency and affordability in maintenance.

The laser cladding experiments will be carried out according to the experimental parameters in Table 3. The preset powder laying speed was $12 \mathrm{~mm} / \mathrm{s}$, the laser power was $2500 \mathrm{~W}$, the spot diameter was $3 \mathrm{~mm}$, the lap rate of laser sintering spot was $50 \%$ and the speed was $16 \mathrm{~mm} / \mathrm{s}$. The specific experiment process is shown in Figure 3-6.

First of all, adopting the method of preset powder, putting the iron-based alloy powder spread to the substrate, as shown in Figure 3. Secondly, laser positioning that has been carried out in Figure 4 was the visual aiding in positioning the alloy onto the substrate in order to carry out the welding - Laser cladding.

Thirdly, sintering powder material on the surface was bonded together with substrate by using a semiconductor laser light source to be a robust structure as shown in Figure 5.

Table 3. Laser cladding test parameters setting

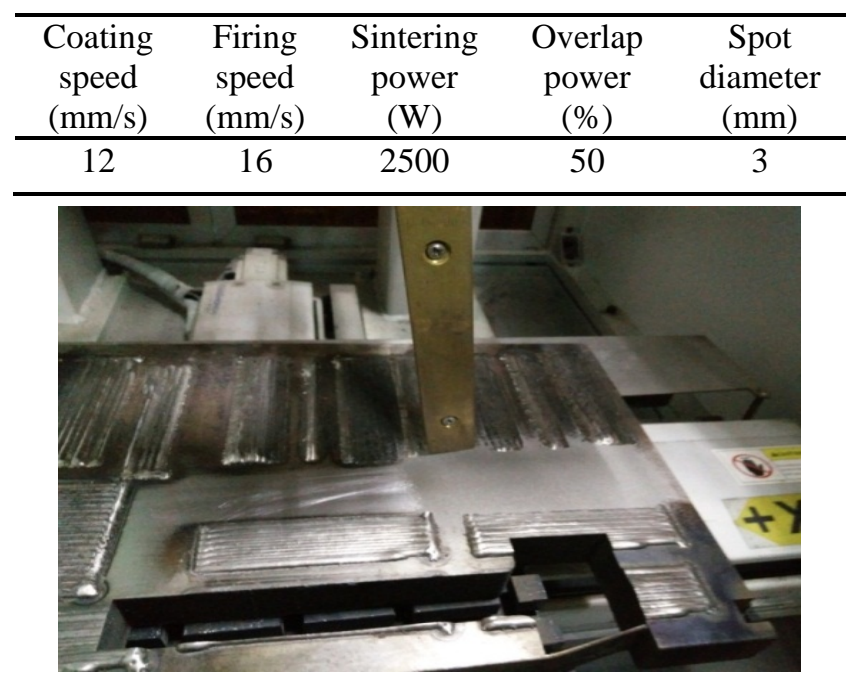

Figure 3. Laying power

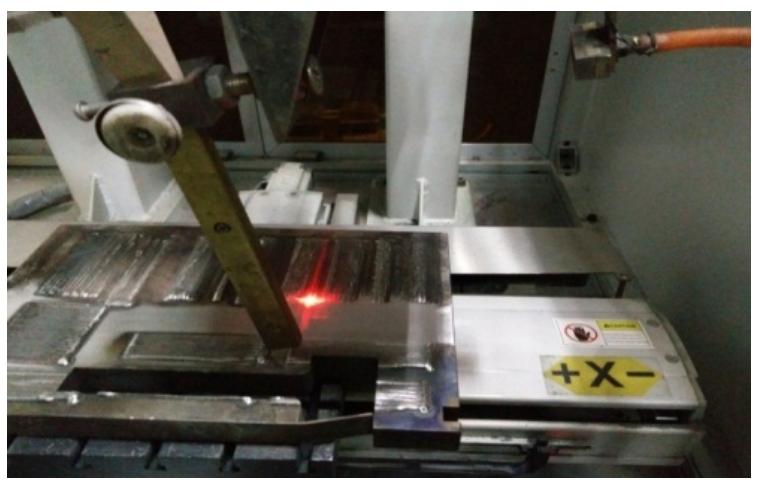

Figure 4. Laser positioning

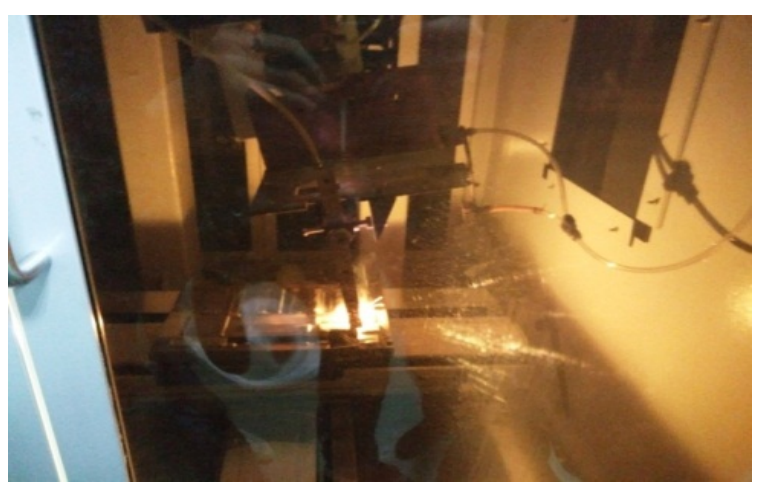

Figure 5. Laser sintering

Finally, the clad specimen was displayed in Figure 6, which reveals the cladding of the alloy to the substrate material.

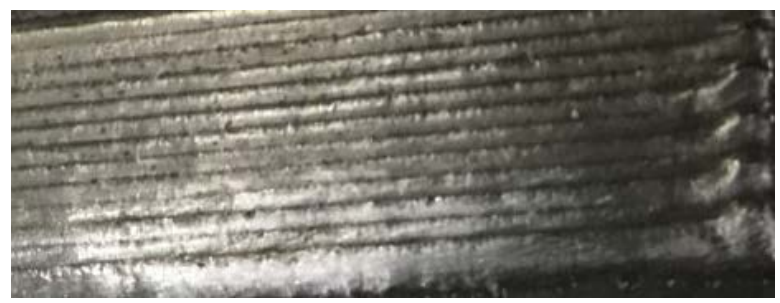


Figure 6. Cladding specimen

\subsection{Wear test}

The test method was the friction and wear experiment which was carried to observe the wear appearances of samples under dry friction condition. The friction and wear equipment was shown in Figure 7. The samples were cut into a standard cylindrical specimen with a diameter of $10 \mathrm{~mm}$ and a length of $12.5 \mathrm{~mm}$ by a wire cutter, and the test parameters of the friction and wear machine were set in Table 4 . The load was $150 \mathrm{~N}$, the rotation speed was 2000r / $\mathrm{min}$, and the time was $5 \mathrm{~min}$ for the dry friction and wear test .

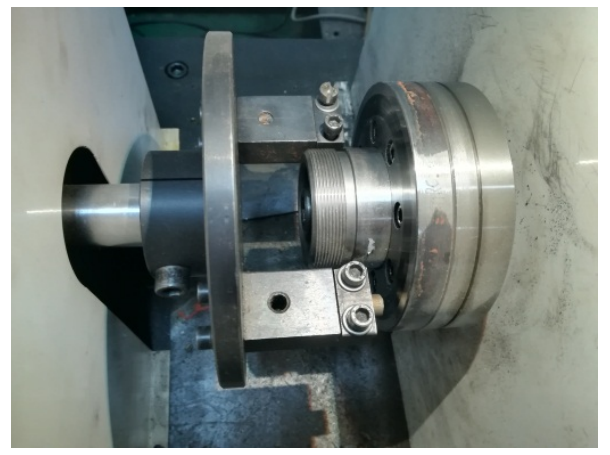

Figure 7. The friction and wear equipment

Table 4. Wear process parameters

\begin{tabular}{cccc}
\hline $\begin{array}{c}\text { Load } \\
(\mathrm{N})\end{array}$ & $\begin{array}{c}\text { Speed } \\
(\mathrm{r} / \mathrm{min})\end{array}$ & $\begin{array}{c}\text { Plate hardness } \\
(\mathrm{HRC})\end{array}$ & $\begin{array}{c}\text { Time } \\
(\mathrm{min})\end{array}$ \\
\hline 150 & 2000 & 60 & 5 \\
\hline
\end{tabular}

\section{Results and discussions}

\subsection{Microstructure observation}

The procedure for heat treatment entailed that samples were first heated to $850^{\circ} \mathrm{C}$, retained for 20 minutes before quenching. The samples were then reheated to the tempering temperature of $250^{\circ} \mathrm{C}$ and kept for 90 minutes and air-cooled. The result revealed smaller and uniform sized grains of the microstructure were obtained for the heat treated samples as shown in Figure 9 (a) and (b). A magnification of $10 \mu \mathrm{m}$ was used in the imaging.

\subsubsection{Non-heat Treatment}

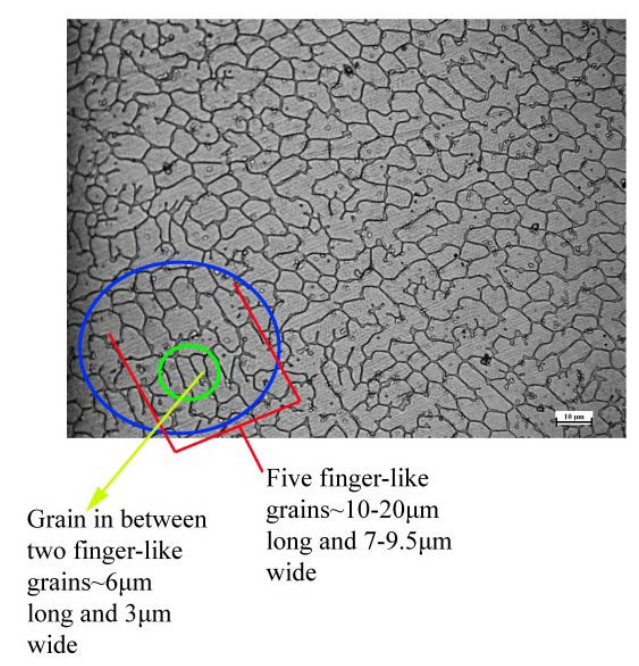

Figure 8(a). Microstructure of non-heat treatment

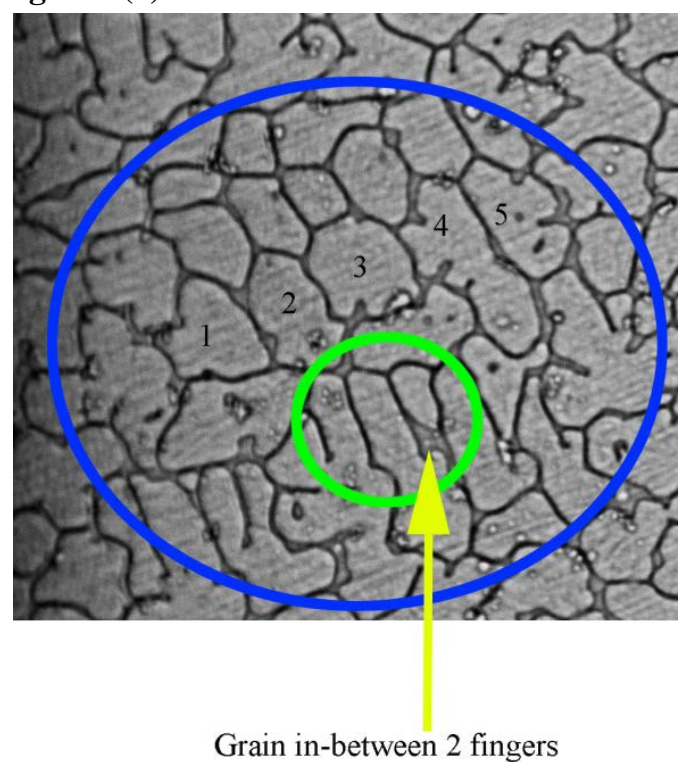

Figure 8(b). Enlarged microstructure of non-heat treatment Within the circle

It is observed that the average grain size range for non-heat treatment scheme from $6 \mu \mathrm{m}$ to $20 \mu \mathrm{m}$ in length on the basis of the microscopic imaging. Besides, it will be further proved from close examination of some interesting features in the located within the microstructure.

A five fingerlike structure located at the lower left part of the microstructure further verifies the findings with dimensions tabulated in Table 5 below. The length for the first fingerlike grain measures $10.2 \mu \mathrm{m}$ whereas the width is $9.8 \mu \mathrm{m}$, likewise the length for the second fingerlike grain is estimated at $10.5 \mu \mathrm{m}$ and width at $7 \mu \mathrm{m}$ measures. The third fingerlike grain is evaluated at a given dimension of $10 \mu \mathrm{m}$ having a width of $9.5 \mu \mathrm{m}$, this is 
followed by the fourth having a dimension of $20 \mu \mathrm{m}$ and a width of $8 \mu \mathrm{m}$ whereas the fifth finger is calculated at $10.5 \mu \mathrm{m}$ and a width of $7.5 \mu \mathrm{m}$ respectively. The area of interest is encircled in blue in Figure 8(a) accordingly, an enlarged version of this area is displayed in Figure 8(b).

Table 5. Dimensions of fingerlike grains in non-heat treatment sample

\begin{tabular}{ccc}
\hline Finger-like grain & Length $(\mu \mathrm{m})$ & Width $(\mu \mathrm{m})$ \\
\hline 1 & 10.2 & 9.8 \\
2 & 10.5 & 7 \\
3 & 10 & 9.5 \\
4 & 20 & 8 \\
5 & 10.5 & 7.5 \\
\hline
\end{tabular}

There is another feature of interest located beneath the first which is a grain in between two fingerlike grains having dimensions of are $3 \mu \mathrm{m}$ width and $6 \mu \mathrm{m}$ length.

\subsubsection{Heat Treatment}

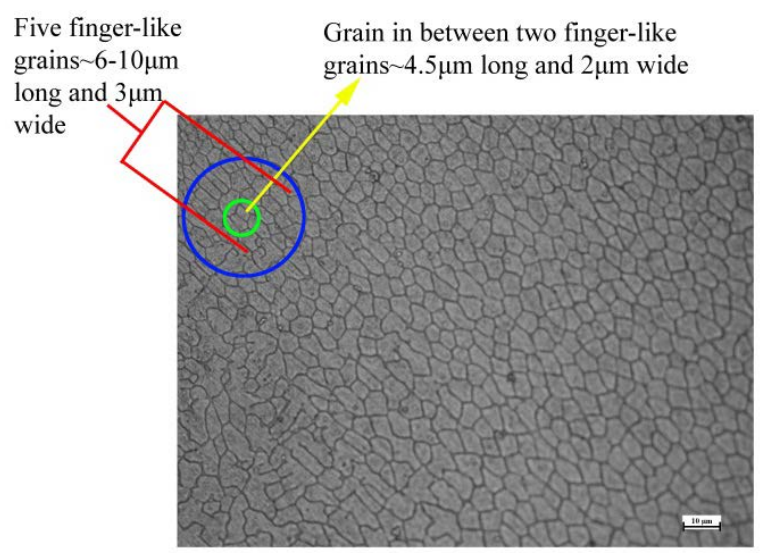

Figure 9(a). Microstructure of heat treatment

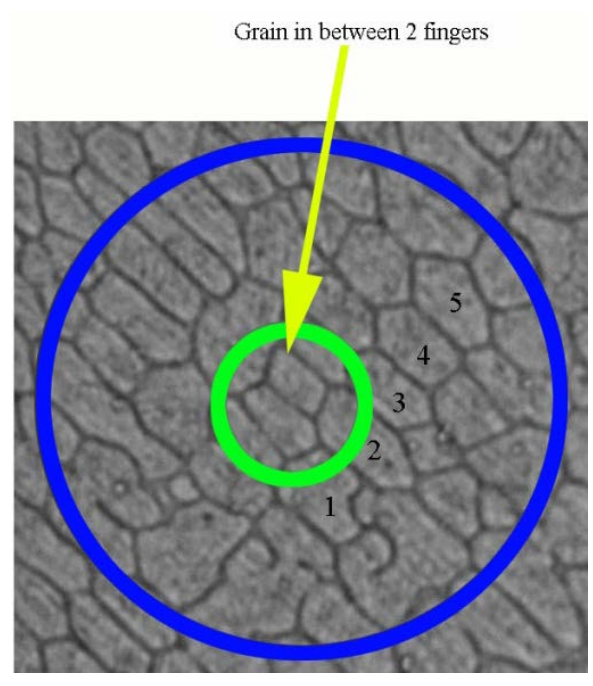

Figure 9(b). Enlarged microstructure of heat treatment within the circle

From the microstructure of the heat treatment scheme, a similar structure of interest is observed at the lower left side of the microscopic image revealing a five fingerlike array. Just like the case of the non-heat treatment scheme, the dimensions of these fingerlike structures are taken and it is found that the sizes ranged from $6 \mu \mathrm{m}$ to $10 \mu \mathrm{m}$ in length. However, the width is constant at $3 \mu \mathrm{m}$ irrespective of the length. The results are tabulated in Table 3 below.

For the first fingerlike grain the length is $10 \mu \mathrm{m}$ whereas the width is $3 \mu \mathrm{m}$, likewise the length for the second fingerlike grain is estimated at $7 \mu \mathrm{m}$ and width at $3 \mu \mathrm{m}$ measures. The third fingerlike growth is evaluated at a given dimension of $10 \mu \mathrm{m}$ having a width of $3 \mu \mathrm{m}$, this is followed by the fourth having a dimension of $6 \mu \mathrm{m}$ and a width of $3 \mu \mathrm{m}$ whereas the fifth finger is calculated at $10 \mu \mathrm{m}$ and a width of $3 \mu \mathrm{m}$ respectively. The area of interest is encircled in blue in Figure 9(a) accordingly, an enlarged version of this area is displayed in Figure 9(b).

Table 6. Dimensions of fingerlike grains in heat treatment

\begin{tabular}{ccc}
\hline Finger-like grain & Length $(\mu \mathrm{m})$ & Width $(\mu \mathrm{m})$ \\
\hline 1 & 10 & 3 \\
2 & 7 & 3 \\
3 & 10 & 3 \\
4 & 6 & 3 \\
5 & 10 & 3 \\
\hline
\end{tabular}

The dimensions of the other interesting feature which is the grain in between the two finger-like grains are $2 \mu \mathrm{m}$ wide and 
4.5 $\mu \mathrm{m}$ long and can be observed as displayed in Figures 9(a) and (b).

\subsection{Hardness Test}

The average hardness of the heat-treatment and non-heat treatment specimens was obtained by three tests as shown in Table 7 and 8 . The average hardness line chart of the clad layer of the heat treatment and non-heat treatment were obtained and while the hardness of the non-heat treatment ranged between $647 \sim 656 \mathrm{HV}$, that of the heat treatment was $669 \sim 686 \mathrm{HV}$. This implies a rise of 1.05 times more than the hardness of the nonheat treatment and consequently offers improved wear resistance thereby reducing the wear of the material as shown in Figure 10. Combined with the above microstructure observation, the microstructure grains are more homogeneous and smaller after heat treatment. Thus, its hardness will increase.

Table 7. The hardness of non-heat treatment from the edge of the cladding to the inside.

\begin{tabular}{ccccc}
\hline Distance/mm & \multicolumn{3}{c}{ Non-heat treatment } & Average \\
\hline 0.3 & 666.22 & 649.98 & 644.2 & 653.47 \\
0.6 & 658.76 & 670.05 & 623.25 & 650.69 \\
0.9 & 677.66 & 659.76 & 609.85 & 649.09 \\
1.2 & 662.47 & 666.23 & 640.64 & 656.45 \\
1.5 & 655.78 & 661.35 & 626.67 & 647.93 \\
1.8 & 663.01 & $672 . .38$ & 633.6 & 648.31 \\
\hline
\end{tabular}

Table 8. The hardness of heat treatment from the edge of the cladding to the inside.

\begin{tabular}{ccccc}
\hline Distance/mm & \multicolumn{3}{c}{ Heat treatment } & Average \\
\hline 0.3 & 668.76 & 689.39 & 671.36 & 676.50 \\
0.6 & 673.81 & 697.39 & 666.38 & 679.19 \\
0.9 & 678.5 & 670.89 & 680.23 & 676.54 \\
1.2 & 663.12 & 666.58 & 679.19 & 669.63 \\
1.5 & 666.22 & 680.3 & 666.85 & 671.12 \\
1.9 & 693.37 & 675.56 & 689.56 & 686.16 \\
\hline
\end{tabular}

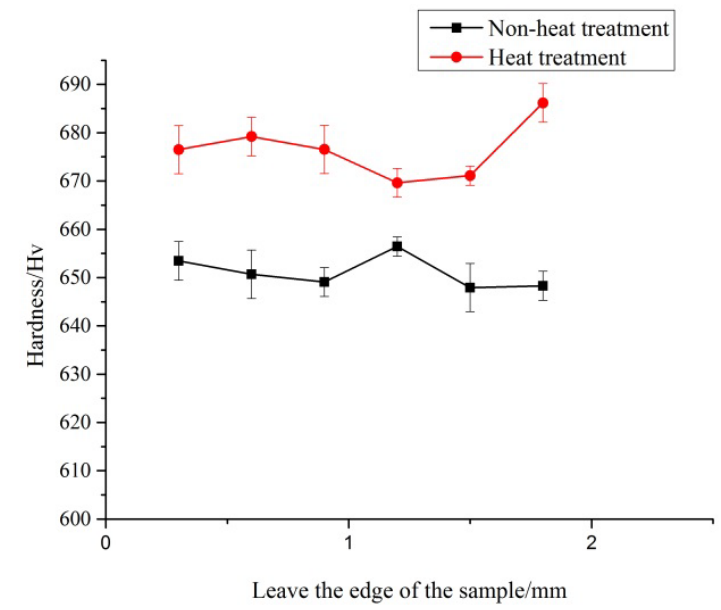

Figure 10. The hardness curves of heat treatment and non-heat treatment

\subsection{Friction and wear}

\subsubsection{Wearing capacity test}

The average results are obtained by three groups of experiments in Table 9. From Figure 11, it can be seen that the quality of wear of the non-heat treatment is $0.23 \mathrm{~g}$ and the heat treatment is $0.12 \mathrm{~g}$. Thus, the quality of the wear of non-heat treatment is greater than that on heat treatment, which is $52 \%$.

Table 9 The quality of wear of the non-heat treatment and heat treatment

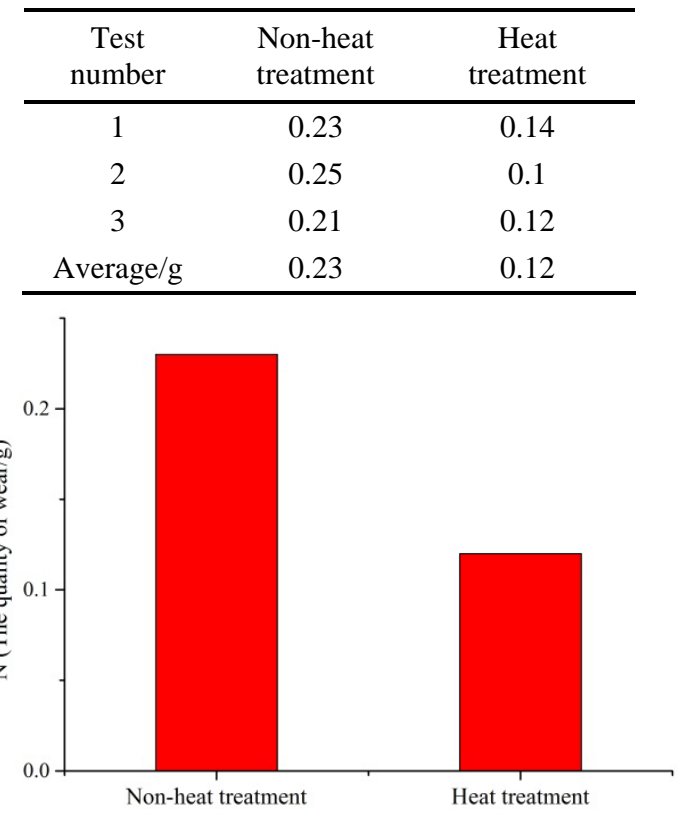

Figure 11. Quality of wear experienced in heat treatment and non-heat treatment schemes

\subsubsection{Friction coefficient}


The friction existing in between the base and clad metal as well as the vertical force acting on one of the surfaces is known as friction coefficient and can be expressed in terms of the wear resistance of the material and roughness of the surface. As a result, it can be deduced that the smaller the friction coefficient, the better wear resistance of the material. In Figure 12, in order to better compare the friction coefficient of the heat treatment and non-heat treatment, here shows the friction coefficient curves of the non-heat treatment and heat treatment. It will be observed from Figure 12 that the friction coefficient is higher in the non-heat treatment compared with the heat treatment.

In order to better verify the results, under the same experimental conditions, heat treatment samples and non-heat treated specimens were repeated 9 sets in Figure 13. The results show that the average friction coefficient of the heat treatment between $0.142-0.151$, the average friction coefficient of the nonheat treatment between 0.156-0.163.

The friction coefficient is enhanced in the heat treated weld sample. Overall result shows that the friction coefficient of the heat treatment scheme is low which implies that the wear resistance is good.

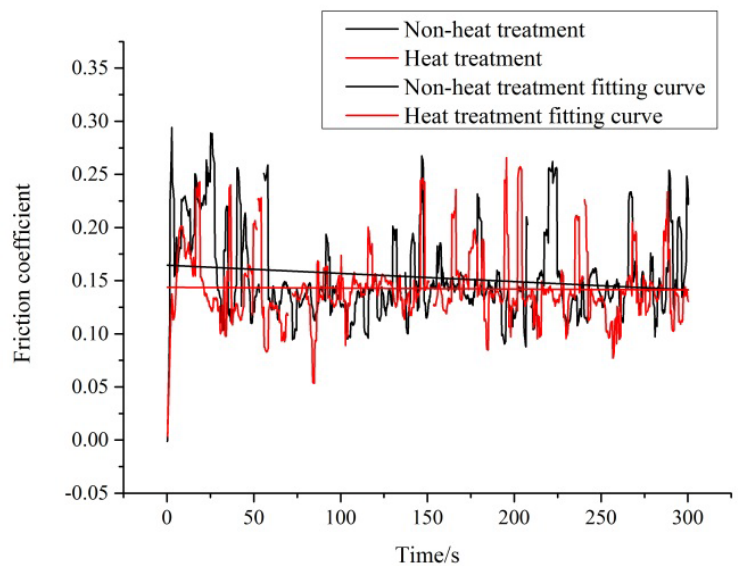

Figure 12. The relationship between time and friction coefficient

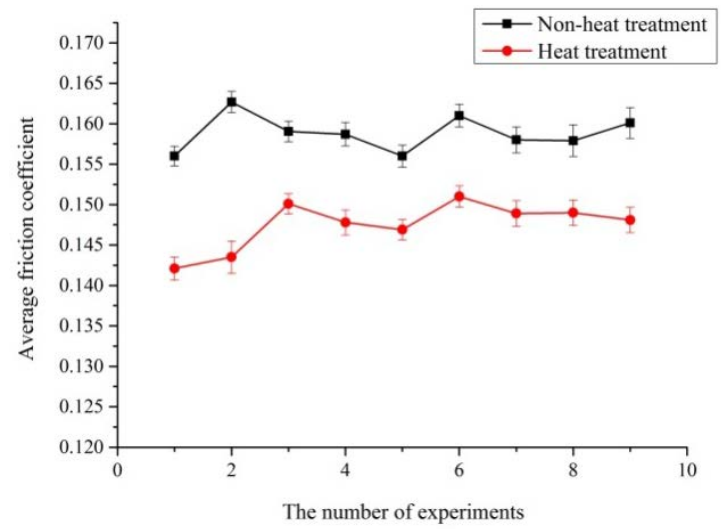

Figure 13. The average friction coefficient of each experiment 3.3.3. SEM test

Wear situation of the non-heat treatment scheme

For precisely comparing the wear morphology of the heattreatment and non-heat treatment samples, the same position of the samples were taken which were $2 \mathrm{~mm} * 2 \mathrm{~mm}$ inside the pin near the center of the plate when the pin was worn. The location is shown in Figure 14.

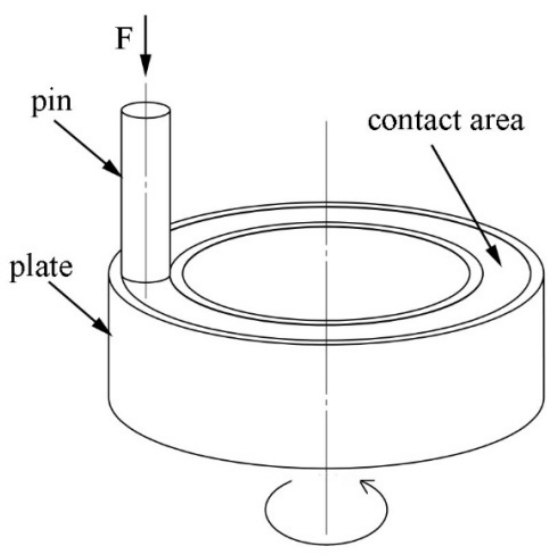

Figure 14. The wear diagram of the pin-plate friction

Figure 15(a) reveals a microstructure of the non-heat treatment carried out on a VEGA II XMU device using a scanning electron microscopy at $20.00 \mathrm{kV}$ and a SEM magnification of 500x.

The results implied the wear situation of the non-heat treatment sample from microscopic examination and image of the microstructure in Figure 15(a), that there exists folds of the order of $20 \mu \mathrm{m}$ wide and $50 \mu \mathrm{m}$ long in length, even $100 \mu \mathrm{m}$ and up to $400 \mu \mathrm{m}$ in length.

The wear situation of the non-heat treatment scheme in Figure 15(a) clearly reveals similar corrugated fold and tearing 
that have occurred along the friction surface. Also present are adhesive bumps and furrows created by the adhesive. The dimensions of these features are reflected in Table 10.

In order to examine this fold closely, six specific areas of interest where highlighted, mapped out and discussed:

Table 10. Dimensions of wear conditions in non-heat treatment and heat treatment microstructures

\begin{tabular}{ccc}
\hline Wear condition & $\begin{array}{c}\text { Non-heat Treatment } \\
\text { microstructure }\end{array}$ & $\begin{array}{c}\text { Heat treatment } \\
\text { microstructure }\end{array}$ \\
\hline $\begin{array}{c}\text { Corrugated fold } \\
\text { and tearing }\end{array}$ & $110 \mu \mathrm{m}$ & None \\
Corrugated fold & $400 \mu \mathrm{m}$ & None \\
Corrugated fold & $400 \mu \mathrm{m}$ & None \\
$\begin{array}{c}\text { Corrugated fold } \\
\text { and tearing }\end{array}$ & $75 \mu \mathrm{m}$ & None \\
$\begin{array}{c}\text { Adhesive bumps } \\
\text { Corrugated fold } \\
\text { and tearing }\end{array}$ & $125 \mu \mathrm{m}$ & None \\
\hline
\end{tabular}

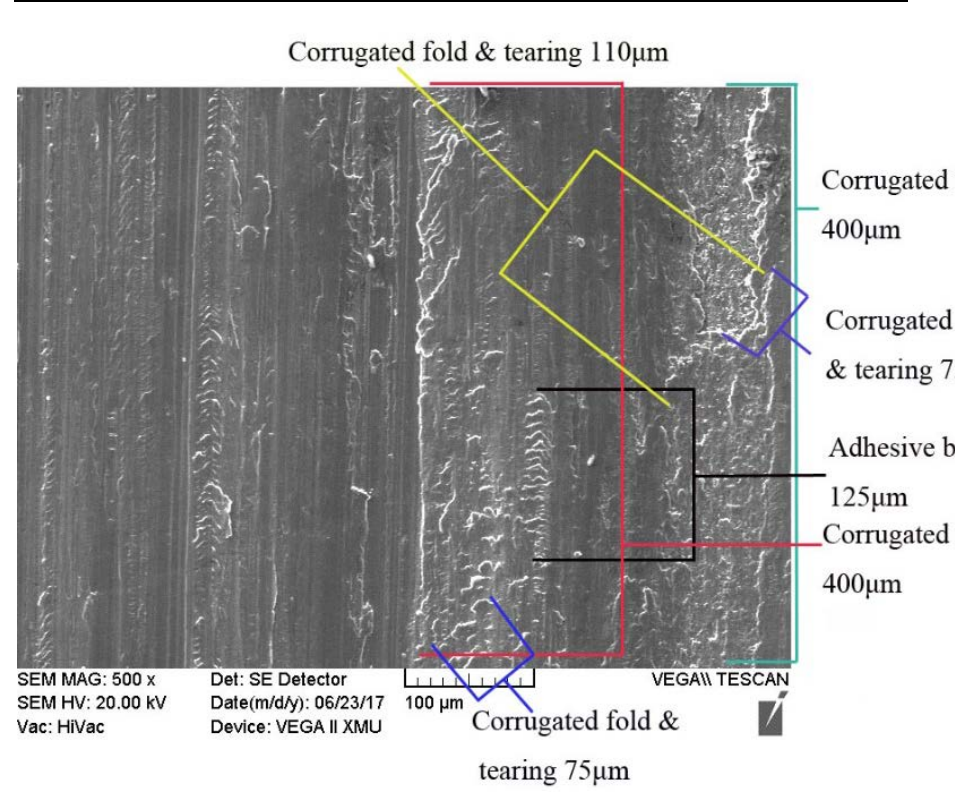

Figure 15(a). Wear situation of non-heat treated sample

The first being the $110 \mu \mathrm{m}$ corrugated fold and tearing located at top right segment of the microstructure which is further enlarged in Figure 15(b). The arrows indicate the different extremes of this fold and tear. Other folds are observed within the region and these clearly reflect the irregularities in the features of the non-heat treatment scheme.

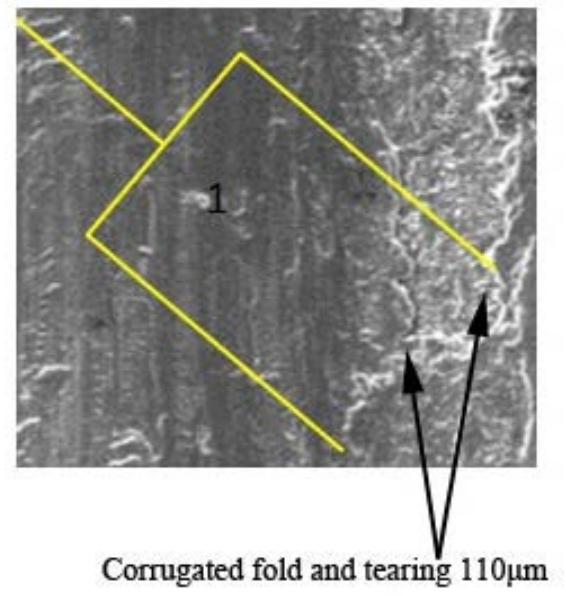

Figure 15(b). Enlarged image of position 1

The second area of interest lies in the middle of the microstructure for the wear situation of the non-heat treatment sample shown in Figure 15(a) and cuts across the whole length of the microstructure. This is the corrugated fold having a dimension of $400 \mu \mathrm{m}$ as seen in Table 10. The arrows in the enhanced image shown in Figure 15(c) further outline the extremes and middle of this fold. Together with the other folds present within the vicinity of this feature, the chapped and coarse nature of the microstructure for the wear situation of the nonheat treatment sample is exemplified and stands out. 


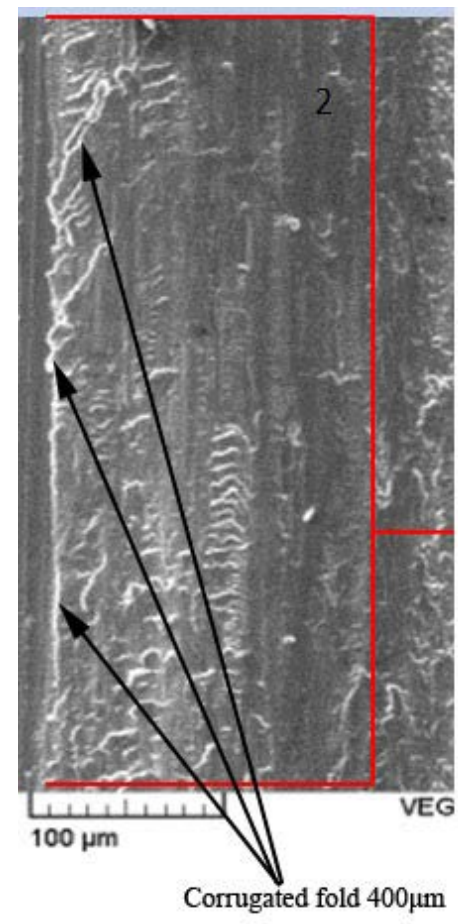

Figure 15(c). Enlarged image of position 2

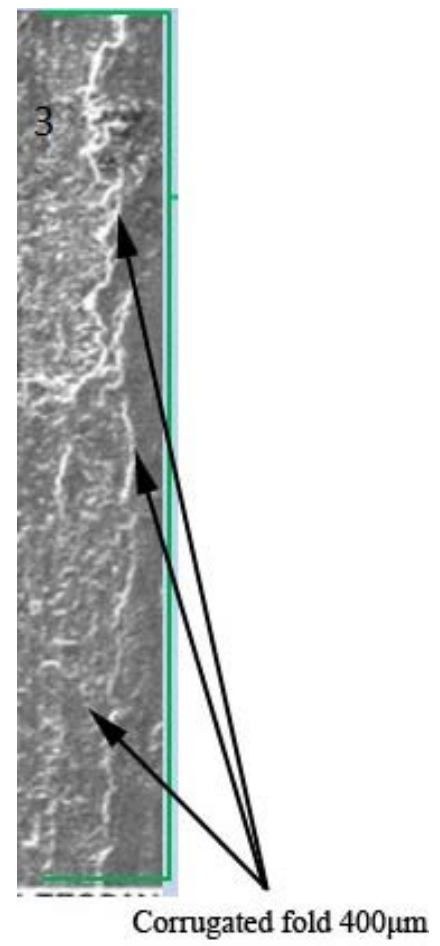

Figure 15(d). Enlarged image of position 3

The third feature is a vertical corrugated fold conspicouly found at the extreme right side of the wear condition of the nonheat treatment microstructure in Figure 15(a). This feature has been zoomed into in Figure 15(d) revealing folds along the whole length of the microstructure; whose nature clearly depicts the rough and uneven terrain of the wear condition of the non-heat treament microstructure in Figure 15(a). It also reveals the degree of usage and wear in the microstructure by reason of friction from the machine parts and constant use. The three arrows clearly show the extent of the corrugated fold and tear which id of the order of $400 \mu \mathrm{m}$.

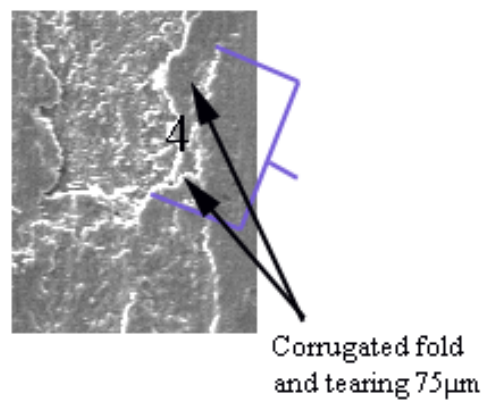

Figure 15(e). Enlarged image of position 4

A corrugated fold of the order of $75 \mu \mathrm{m}$ long is also found situated at the top right quadrant of the wear condition of the nonheat microstructure in Figure 15(a). This further enlarged in Figure 15(e) above with the arrows indicating the extreme ends of this tear and fold. Other tears and folds are also observed within the vicinity which further reveals the nature of the wear condition of the non-heat treatment microstructure in Figure 15(a) as jagged and worn out from friction of mechanical parts and usage.

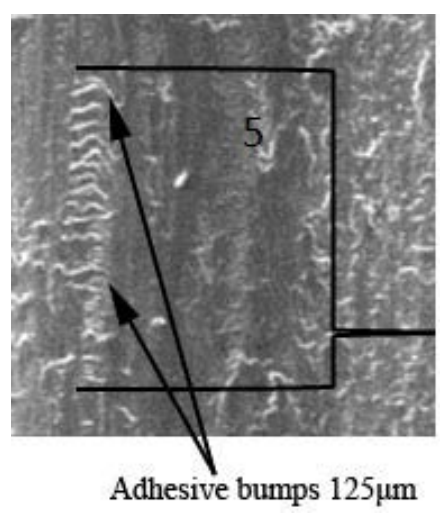

Figure 15(f). Enlarged image of position 5

There are adhesive bumps across the wear scheme of the non-heat microstructure in Figure 15(a) located at the lower right quadrant. The cross sectional length of these adhesive bumps has a magnitude of $125 \mu \mathrm{m}$ and the arrows depict the spread of these bumps as magnified in Figure 15(f). The nature of the adhesive 
bumps reveals the abrasive, bumpy and textured terrain of the wear condition of the non-heat treatment microstructure in Figure 15(a).

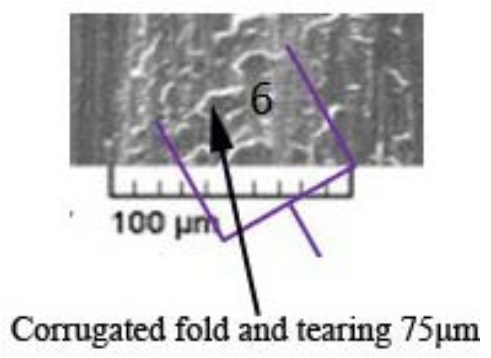

Figure 15(g). Enlarged image of position 6

The mid-section of the lower end of the wear condition of the non-heat microstructure in Figure 15(a) reveals another corrugated fold and tearing measuring up to $75 \mu \mathrm{m}$ in dimension. The arrow pointing to the feature in the magnified Figure 15(g) portrays a ridged and rugged pattern and nature of the wear condition of the non-heat microstructure in Figure 15(a). There are other corrugated folds observed within the vicinity of this fold, which further contribute towards unveiling the choppy and serrated style of the microstructure for the wear situation of the non-heat treated sample.

Wear situation of the heat treatment scheme

The wear condition of the heat treatment microstructure is displayed Figure 16(a) which is a microstructure of the heat treatment obtained from a VEGA II XMU device using a scanning electron microscopy at $20.00 \mathrm{kV}$ at a SEM magnification of 500x.

The surface of the heat treatment scheme reveals a relatively smooth surface compared with the wear condition of the non-heat treated microstructure in Figure 16(a). There also exists shallow folds and peeling parallel to the direction of friction. This clearly implies that the preferred scheme of the two scenarios is the wear of the heat treatment.
No corrugated fold \&tearing

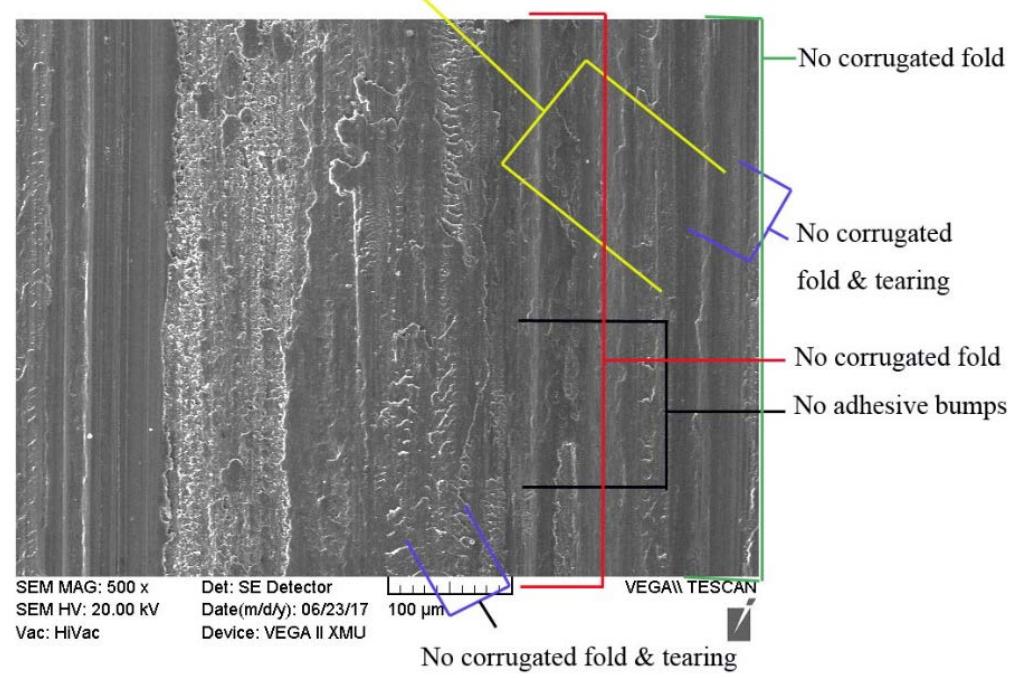

Figure 16(a). Wear situation of heat treated sample

Just as with the microstructure for the wear situation of the non-heat treatment sample, six similar areas of interest have also been identified, examined and discussed in the light of the findings as follows:

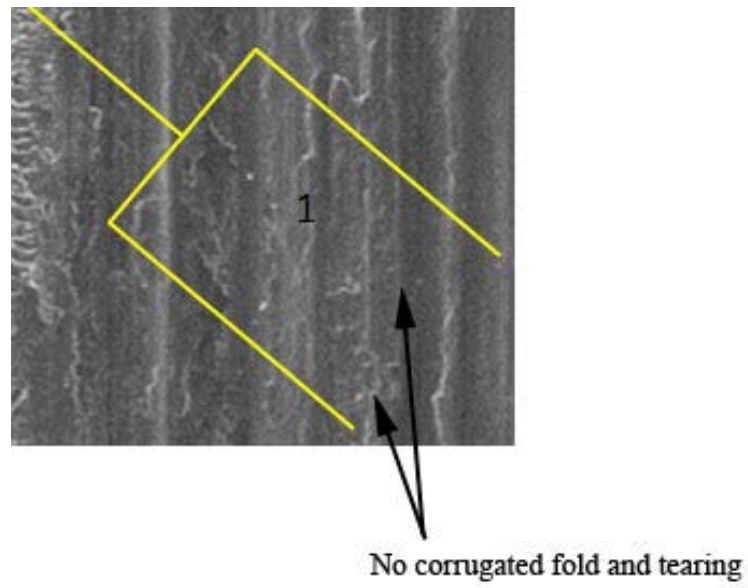

Figure 16(b). Enlarged image of position 1

The first sector to be discussed located at the top right segment of the microstructure in Figure 16(a) reveals that no corrugated fold or tearing is present. The specific corrugated fold and tearing feature found in Figure 15(b) is absent in Figure 16(b) here which clearly indicates the effect of the heat treatment on the microstructure in eliminating folds and tears hence prolonging the in-service life of the material.

The surrounding folds and rough terrain present in Figure 15(b) are also absent generating a smooth surface in Figure 16(b). 


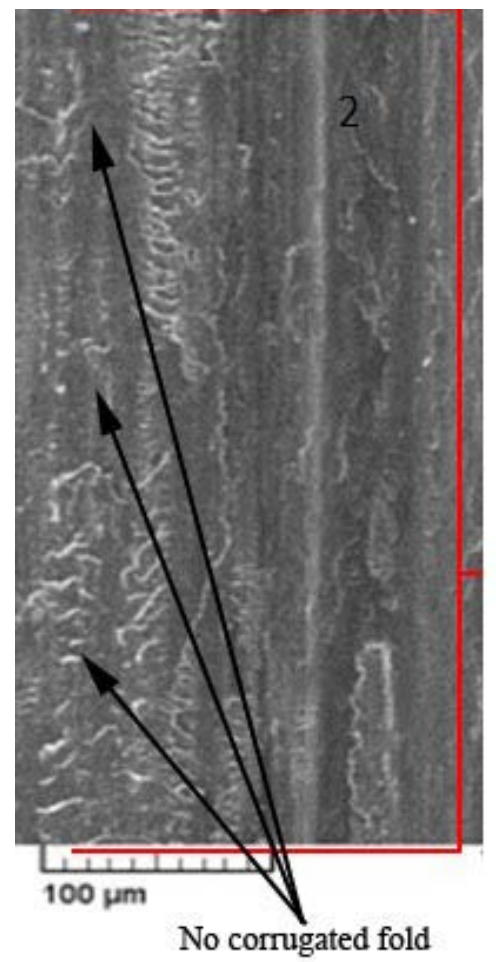

Figure 16(c). Enlarged image of position 2

The second area of interest is situated at the middle of the microstructure in Figure 16(a) across the length of the microstructure. It is observed that there is no corrugated fold present in the exact position as illustrated by the arrows in Figure 16(c). This portrays the effect of heat treatment in the wear condition of the microstructure in that it eradicates the chapped and coarse features presenting a smooth scheme which is advantageous in enhancing longevity of the material.

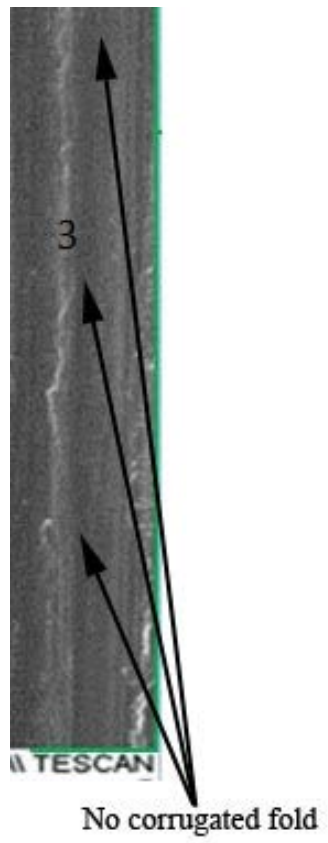

Figure 16(d). Enlarged image of position 3

At the extreme right of the microstructure in Figure 16(a) there is a smooth and clear section along the whole length, which when examined closely in Figure 16(d) confirms the fact that the there is no corrugated fold present. In the place of the $400 \mu \mathrm{m}$ fold found in Figure 15(d) is the even plane feature of wear condition of the heat treatment microstructure which is beneficial to the long span of the material involved. It is worthy to note that the surrounding folds present in wear condition of the non-heat treatment scheme in Figure 15(d) is also absent in this heat treated scheme.

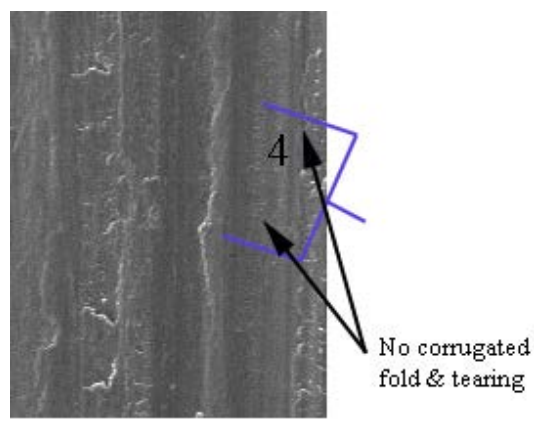

Figure 16(e). Enlarged image of position 4

Within the top right quadrant of the wear situation of heat treatment sample in Figure 16 (a) lies the no corrugated fold and tearing scenario. This is further illustrated at a closer range in Figure 16(e) which reveals the complete absence of the $75 \mu \mathrm{m}$ corrugated fold and tearing that was present in Figure 15(e) of 
the wear situation of the non-heat treated sample. The clear outcome in the results clearly proves the efficacy of the heat treatment in eradicating the jagged and worn out features of wear thereby preserving the durability of the material under discussion.

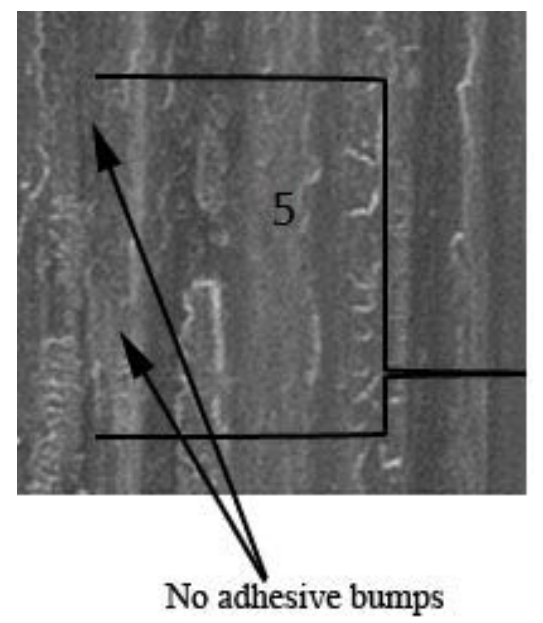

Figure 16(f). Enlarged image of position 5

The lower right segment of the wear situation of the heat treatment microstructure in Figure 16(a) houses an interesting discovery of no adhesive bumps. This demonstrated in the Figure 16(f) with the arrows pointing towards the smooth terrain. The $125 \mu \mathrm{m}$ adhesive bumps which are displayed in Figure 15(f) are absent leaving behind a very smooth terrain in the microstructure. This is a clear indication that heat treatment scheme rids off the bumpy and textured terrain of the non-heat treatment microstructure revealing the levelled terrain in the wear condition which is conducive for the long lasting performance of the material.

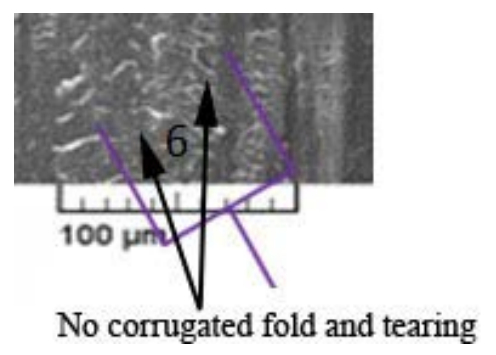

Figure 16(g). Enlarged image of position 6

The mid lower segment of the wear condition of the heat treatment microstructure is displayed Figure 16 (a) reveals the absence of the $75 \mu \mathrm{m}$ corrugated fold and tearing conspicuously presented in Figure 15(g). The result is further analyzed in Figure 16(g) where the arrows depict the presence of the smooth terrain of the wear condition of the heat treatment microstructure. The surrounding folds and tears are also eradicated, further buttressing the fact that the wear condition of heat treatment scheme provides appropriate situation for longevity of material.

Comparison of the wear situation of the heat treatment and non-heat treatment scheme from Figures 15(a-g) and 16(a-g) as well as Table 10:

The wear situation of the non-heat treatment scheme in Figure 15(a) clearly reveals similar corrugated fold and tearing that have occurred along the friction surface. Also present are adhesive bumps and furrows created by the adhesive. The dimensions of these features are reflected in Table 10.

The surface of the heat treatment scheme reveals a relatively smooth surface compared with the wear condition of the nonheat treated microstructure in Figure 16(a). There also exists shallow folds and peeling parallel to the direction of friction.

Furthermore, from the results of the dimensions of the specific folds, tearing and adhesive bumps present in the wear condition of the non-heat treated microstructure as displayed in Table 10, it is obvious that there are no exact folds, tearing, adhesive bumps present in the wear condition of the heat treated microstructure which provides the potential for durability with usage of material, machine parts and time. This clearly implies that the preferred scheme of the two scenarios is the wear of the heat treatment.

\section{Conclusions}

The results of heat treatment after the laser cladding ironbased alloy are as follows:

(1)The microstructure of the non-heat treatment samples and the heat-treated samples was observed by the five finger method. As a result, it is observed that the average grain size for the nonheat treatment scheme ranges from $10 \mu \mathrm{m}$ to $20 \mu \mathrm{m}$ in length and from $7 \mu \mathrm{m}$ to $9.8 \mu \mathrm{m}$ in width. However, the sizes ranged of heat treatment sample from $6 \mu \mathrm{m}$ to $10 \mu \mathrm{m}$ in length, and the width is constant at $3 \mu \mathrm{m}$ irrespective of the length. It shows that the microstructure after the heat treatment is more homogeneous and smaller.

(2)The wear resistance of the heat-treatnent and non-heat treatment specimens was compared by measuring the microhardness, the quality of wear, the friction coefficient and 
the wear profile. The results show that the hardness of the heat treatment is 1.05 times than the non-heat treatment, the quality of the wear of non-heat treatment is $52 \%$ than that on heat treatment, the average friction coefficient of the heat treatment is 87\%-92\% than that on non-heat treatment.

In summary, the heat treatment microstructure is more homogeneous, larger hardness, less wear and tear, the friction coefficient is smaller, the wear morphology is smooth. Therefore the heat treatment can significantly improve the wear resistance of laser cladding iron-based alloy samples.

\section{Future work}

This paper is mainly based on the working background of coal mine hydraulic support column wear, set up specific friction and wear test parameters to conduct experiment, meanwhile did some performance tests. It is concluded that heat treatment can significantly improve the wear resistance of laser clad iron-based alloy. In the future, it will be verified its wear resistance of iron based alloy of the laser cladding and heat treatment and whether it will be applied to more occasions. The orthogonal friction and wear tests are carried out on different loads, sliding speeds and the hardness of the disc. Thus, the quality of wear and friction coefficients are taken as experimental factors for numerical analysis and a series of performance tests, the best wear resistance test parameters combinations under various working conditions will be obtained.

\section{Acknowledgments}

This research is supported by the following projects:

The Natural Science Project of Education Office of Shaanxi Province (No.15JK1484);

\section{References}

1. Barnett R N, Hannu Häkkinen †, And A G S, et al. Hydrogen Welding and Hydrogen Switches in a Monatomic Gold Nanowire[J]. Nano Letters, 2016, 4(10):1845-1852.

2. Lampa C, Kaplan A F H, Powell J, et al. An analytical thermodynamic model of laser welding[J]. Journal of Physics D Applied Physics, 2016, 30(9):1293.

3. Khan R, Bhatty M B, Iqbal F, et al. Effect of welding parameters on the mechanical and microstructural properties of friction stir welded AA- 2014 joints[J]. 2016, 146(1):012055.

4. Xu M, Jiang J, Li B, et al. Experimental characterizations of laser cladding of iron- and nickel-based alloy powders on carbon steel
1045 for remanufacturing[J]. Proceedings of the Institution of Mechanical Engineers Part L Journal of Materials Design \& Applications, 2016.

5. Kaushal S, Singh B, Gupta D, et al. An approach for developing nickel-alumina powder-based metal matrix composite cladding on SS-304 substrate through microwave heating[J]. Journal of Composite Materials, 2017:002199831774073.

6. Hongxia Zhang,Huijun Yu,Chuanzhong Chen. Microstructure and wear resistance of composite coating by laser cladding Ni60A/B4C pre-placed powders on Ti-6Al-4V substrate[J]. Science and Engineering of Composite Materials, 2017, 24(4).

7. Wang W J, Fu Z K, Cao X, et al. The role of lanthanum oxide on wear and contact fatigue damage resistance of laser cladding Fe-based alloy coating under oil lubrication condition[J]. Tribology International, 2016, 94:470-478.

8. Lewis S R, Fretwell-Smith S, Goodwin P S, et al. Improving Rail Wear and RCF Performance using Laser Cladding[J]. Wear, 2016, 366-367:268-278.

9. Lu Y, Ren L, Wu S, et al. CoCrWCu alloy with antibacterial activity fabricated by selective laser melting: Densification, mechanical properties and microstructural analysis[J]. Powder Technology, 2017.

10. Weng F, Chen C, Yu H. Research status of laser cladding on titanium and its alloys: A review[J]. Materials \& Design, 2014, 58(6):412425.

11. M. Sitarz,A. Kurc-Lisiecka,W. Gamon. Surface Analysis of Railway Buffers Heads Covered with Bronze Using Laser Cladding[J]. Archives of Foundry Engineering, 2017, 17(2).

12. White R A, Abergel R P, Lyons R, et al. Biological effects of laser welding on vascular healing.[J]. Lasers in Surgery \& Medicine, 2010, 6(2):137-141.

13. Sehgal, Surinder K. Processing and characterization of composite cladding through microwave heating on martensitic steel[J]. Proceedings of the Institution of Mechanical Engineers Part L Journal of Materials Design \& Applications, 2015, 162(12):297299.

14. Beijing Xue,Litong Guo,Xiaoyuan Chen,Yu Fan,Xuanru Ren,Baoe Li,Yihan Ling, Yinghuai Qiang. Electrophoretic deposition and laser cladding of bioglass coating on $\mathrm{Ti}[\mathrm{J}]$. Journal of Alloys and Compounds, 2017, 710. 
15. L. Chen,X.M. Liu,F.X. Huang,J. Chen. Study on Effect Factors and Control Process of Match between Cladding Powder and Laser Beam in Coaxial Powder Feeding Laser Cladding[J]. Applied Mechanics and Materials, 2012, 1867(184).

16. Gladys Schnier,James Wood,Alexander Galloway. Investigating the Effects of Process Variables on the Residual Stresses of Weld and Laser Cladding[J]. Advanced Materials Research, 2014, 3278(996).

17. Luo K Y, Jing X, Sheng J, et al. Characterization and analyses on micro-hardness, residual stress and microstructure in laser cladding coating of 316L stainless steel subjected to massive LSP treatment[J]. Journal of Alloys \& Compounds, 2016, 673:158-169.

18. Hurtado A M, Francis J A, Stevens N P C. An assessment of residual stress mitigation strategies for laser clad deposits[J]. Materials Science \& Technology, 2016, 32(14):1-11.

19. Tao Y F, Jun L I, Ying-Hao L Ü, et al. Residual stress distribution in different depths of TiNi/Ti 2 Ni-based laser clad coating prepared at different environmental temperatures[J]. Transactions of Nonferrous Metals Society of China, 2017, 27(9):2043-2054.

20. Kraetzsch M, Standfuss J, Klotzbach A, et al. Laser Beam Welding with High-Frequency Beam Oscillation: Welding of Dissimilar Materials with Brilliant Fiber Lasers[J]. Physics Procedia, 2011, 12(1):142-149.

21. Zou J, Yang W, Wu S, et al. Effect of plume on weld penetration during high-power fiber laserwelding[J]. Journal of Laser Applications, 2016, 28(2):022003. 